Visualizing Objects, Places, and Spaces: A Digital Project Handbook

\title{
Isaac, Enslaved Carpenter
}

\section{Madeline Pannell}

Published on: Jul 14, 2021

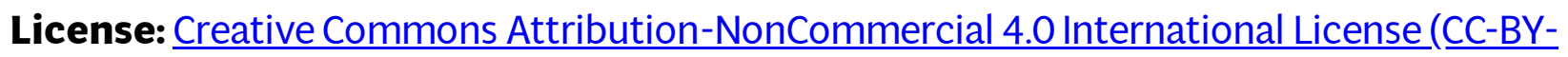
NC 4.0). 


\section{Team}

Project Developer: Madeline Pannell, Undergraduate Researcher, Center for Digital Editing, University of Virginia

Project Supervisor: Erica Cavanaugh, Project Developer, Center for Digital Editing

\section{Project URL}

https://arcg.is/1PCjOb

\section{Project Abstract}

After "Shoemaker Will,"- the enslaved individual mentioned most frequently in the Mount Vernon Ledger 1794-1796 was a carpenter named Isaac. Investigating Isaac's story using the Financial Papers Project site and the Papers of George Washington index revealed a greater story of a family divided across the lines of freedom and slavery, distance and mobility. To present the narrative of Isaac's family, I created an ArcGIS StoryMap with embedded data visualizations, including an interactive family tree, to demonstrate how financial and labor records can reveal the larger story of a family. Visual information representation creates an accessible and coherent expanded understanding of the lives of an enslaved family. 


\section{KITTY'S FAMILY TREE}

This family tree displays Kitty, an enslaved spinner, along with her husband Isaac, her daughters, and their immediate families.

Law Lewis Peter Parke Custis possibly died/not in the record —Freed —Unknown Individual

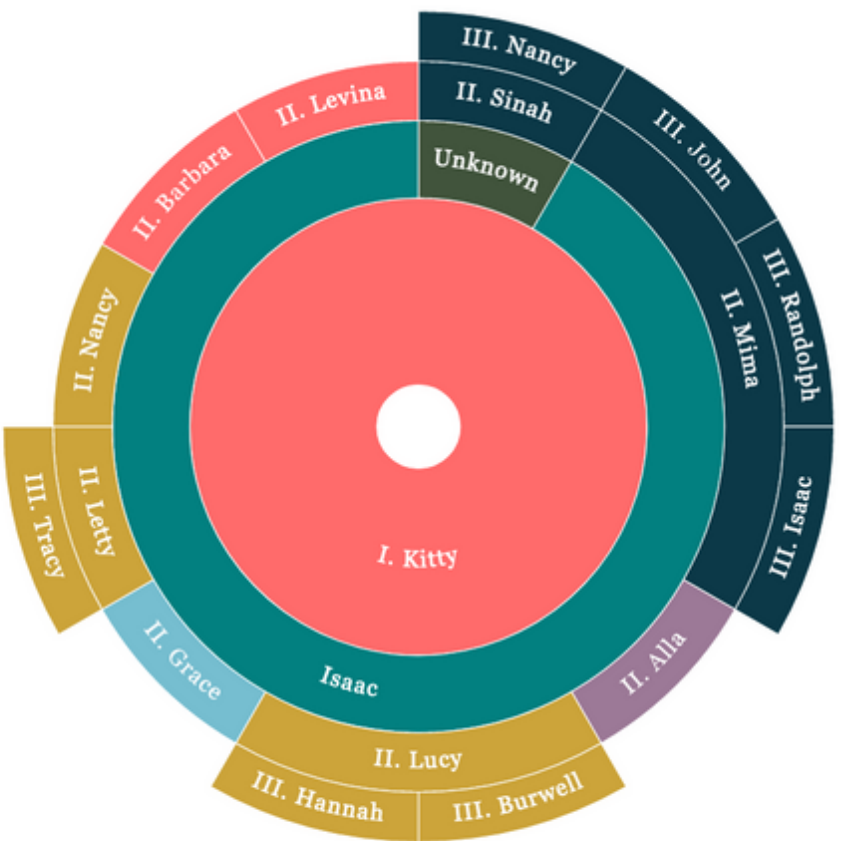

[View the interactive graphic here.] This graphic shows Isaac and Kitty's family from their children to their grandchildren, using information from Mount Vernon records up until the year 1802. The last known mentions for many of the individuals named in this graphic were in the slave lists collected for the Custis inheritance. Each color corresponds with each individual's status of freedom in 1802, when all of the dower slaves were divided between the households of the four Custis heirs. In other words, this graphic shows how Isaac and Kitty's family was torn apart: across distance, mobility, and freedom. 


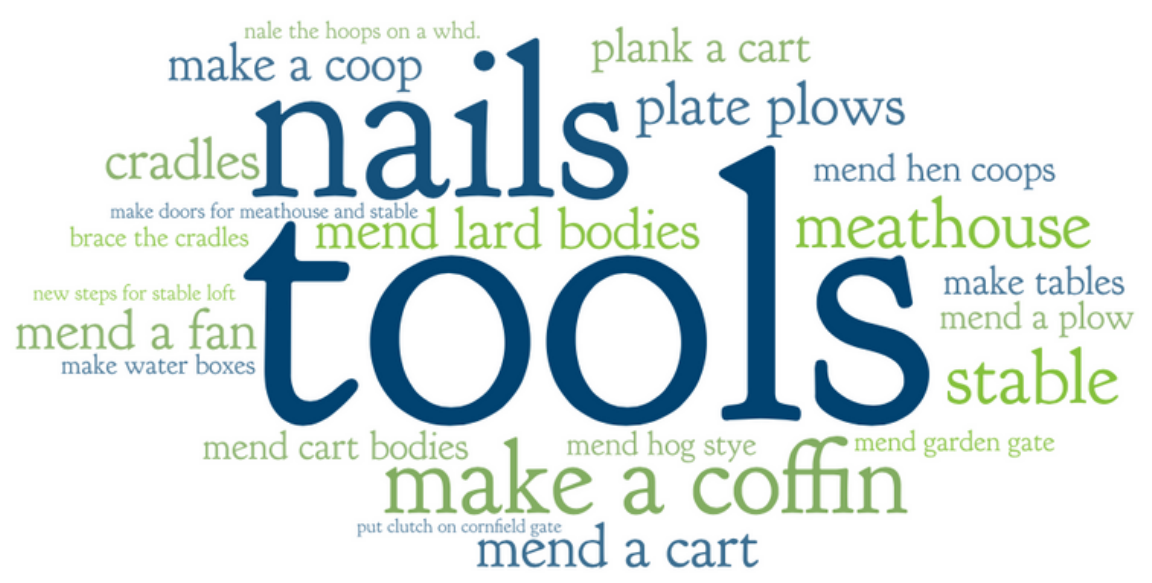

This word cloud represents the relative frequency of each task assigned to Isaac the carpenter in the Mount Vernon Ledger 1794-1796.

Isaac raised...

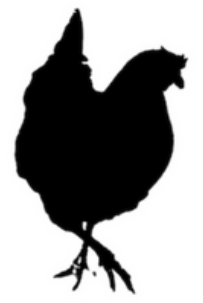

over a dozen chickens.

- July 25th, 1796: "paid carpenter Isaac for Dozen chickens" at 1/ per chicken for 12/ total (12)

- August 21st, 1799: "By Carpenter Isaac pd him for 8 Galls honey and a balance for Chickens" (no amount listed) (13)

At the 1796 rate of 1 / per chicken, it would have taken 1,000 chickens to raise the equivalent of Kitty's value in 1802 of £50. Kitty’s whole family—including herself, her daughters, and her grandchildren-had a total value of $£ 603$, which would have been equivalent to approximately 12,060 chickens.

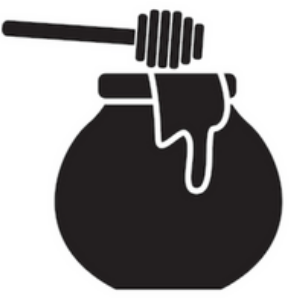

\section{at least 15 gallons of honey.}

- March 28th, 1791: "By Isaac pd him for 2 Gallons Honey" at 5/ per gallon for $10 /$ total (14)

- July 16th, 1797: "By 5 Galls honey bought of Isaac @ $10 / "$ for £2.10.00 total (15)

- August 21st, 1799: "By Carpenter Isaac pd him for 8 Galls honey and a balance for Chickens" (no amount listed) (16)

Although the specific reason Isaac chose to use his time for independent projects is unknown, the data above shows how

much he earned for his work and how those earnings compare to the cost it would have taken to buy the freedom

of his family members (his own freedom being secured through Washington's will). 


\section{Time Needed}

When did you begin this project? When did you complete this project?

Time Span: September 5, 2019 - February 10, 2021

Length: $1.5+$ years

\section{Outcomes}

What is the outcome of the project?

This is part of a series of visualizations I've worked on to present the lives of enslaved individuals at Mount Vernon through the lens of Washington's financial documents. Currently, I don't have plans to create more profiles as I am transitioning to different kinds of work for the CDE, but these visualizations are part of the Washington Papers Project's focus on highlighting the voices and experiences of enslaved individuals at Mount Vernon. I have also completed "Shoemaker Will": William Lee, Mount Vernon Ledger 1794-1796.

\section{Resources}

What tools, resources, programs, or equipment did you use for this project?

- ArcGIS Story Maps: I decided to use this tool predominantly for narrative presentation, rather than for its mapping functions.

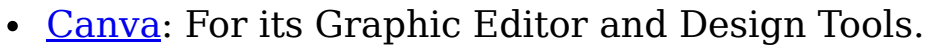

- Oxygen XML Editor : This tool was used to draft the content document for the preexisting coding of the interactive family tree developed by Erica Cavanaugh. The code had been designed for a previous project, but using Oxygen allowed me to write a document with my research content so that the code could present my data.

\section{Funding}

Please describe any costs incurred for this project, and (if relevant) how you secured funding for these costs. 
The licenses for Oxygen XTML Editor and StoryMaps, as well as the server space, were provided by the University of Virginia.

\section{Workflow}

Please give an overview of the workflow or process you followed to execute this project, including time estimates where possible.

I started with the basis of transcription and textual/data analysis I had done for the George Washington Financial Papers Project. Analyzing this metadata had given me a wealth of information about the enslaved community at Mount Vernon: some of this information I had used to curate my earlier project on William Lee's life. From this data collection, I focused in on the information relevant to Isaac's workload and life. Next, I did further research to more fully capture the archival record of Isaac's life, including his family and every detail about their lives recorded, which took roughly a month. I collected all the information on Isaac and his family I could find from other Mount Vernon financial records, letters, and ledgers using the Papers of George Washington digital edition. I spent the successive months developing the narrative of Isaac and Kitty's family from this information, assembling my research into coherent sections and graphic visualizations. During this time, I also wrote the file for Isaac and Kitty's interactive family tree. Finally, I gathered all of the information and analysis into the StoryMap and wrote accompanying prose.

\section{Challenges \& Opportunities}

What, if anything, changed between beginning your project and its current/final form?

I transitioned from a focus on Isaac himself, and the work he did around Mount Vernon, to a greater focus on Isaac's family and their stories. I chose to do this because one of my main goals with the project was to highlight the humanity of the lives of the enslaved individuals at Mount Vernon. Family was one of the most specific glimpses of humanity that records capture, so elaborating and illustrating this aspect of life was significant to capturing Isaac's person and character.

Is there anything specific you wish you had known when beginning your project that might help other people to know? 
Planning out the vision of a finished project earlier and creating an accompanying projected timeline results in more efficient and coherent results. I had planned on using the phrase cloud from the beginning of my project planning, since it was one of the ways that I had visualized the financial metadata to draw conclusions. Also, the interactive family tree was something I had intended to use from fairly early on in the project development process (once I had recognized the significance of portraying Isaac's family). My challenge lay primarily in figuring out how to fit the different pieces of research into a narrative, as well as digital representation for the pieces I hadn't started with. Thus, my timing for the individual parts was not very streamlined, and I had to go back and redo parts of the project to better present the narrative: for example, the sections that show the coffins constructed by Isaac and his independent labor.

Moving forward, the lesson I have learned is to invest time at the beginning of my projects to envision the full narrative and break down the smaller steps required for building it. It will be helpful to estimate how much time each of those steps will take, too. For example, I did not spend a lot of time looking into Isaac's independent work when I initially began shaping Isaac's narrative, but I realized that it could carry more significance for the project. I had to go back and do a good bit more research to elaborate on the information I had.

\section{Next Steps}

Do you have any plans to follow up on this project or work on something similar in the future?

At the moment, I'm transitioning to doing web design work for the Center for Digital Editing, so it's uncertain whether I will create any more profiles of the enslaved community at Mount Vernon. 